\title{
RESILIENCE IN AGRICULTURE: HOW CAN CAP DIRECT PAYMENTS IMPACT IT?
}

\author{
*Agnẻ Žičkienė \\ Lithuanian Institute of Agrarian Economics, Lithuania \\ *Corresponding author's email: agne.zickiene@laei.lt
}

\begin{abstract}
The increasing frequency and magnitude of adverse meteorological events together with the growing uncertainty in the upcoming future pose more and more challenges to agriculture. Therefore, the future sustainability of agriculture will increasingly depend on its resilience, i.e. the capacity to withstand various perturbations and to recover from them. The direct payment (DP) system of the EU Common agricultural policy (CAP) is the most financed EU support scheme for agriculture; however, research on its impact on the important phenomena of resilience is scarce and fragmented. In order to fill this gap, this paper offers an extensive overview of literature and a summarized list of factors that are mentioned most often as potentially influencing the agricultural resilience. Based on this, the possible impact of DP on agricultural resilience was analyzed. In this paper, it is argued that this impact is transferred mostly through changing farms' financial capabilities as well as farmers' attitudes and behavior, and is both positive and negative. Such phenomena as low crop insurance uptake and decrease in productivity may be due to the overcrowding effects of direct payments. These hypotheses are being tested in a survey, conducted in the meantime.
\end{abstract}

Key words: resilience, agriculture, CAP direct payments.

\section{Introduction}

Agricultural sector is exposed to various types of risks: economic, climatic, environmental, political, technological, etc. Several types of risks often turn out simultaneously, exacerbating each other's negative consequences. Besides that, agricultural markets are very specific, defined by high seasonality, long production cycles and short shelf-life, which make these markets especially vulnerable to various risks with significant repercussions on a wider scale. Although farmers have always been facing most of the above mentioned risks and have adapted to them more or less successfully, the speed of the ongoing changes, the increasing frequency and magnitude of adverse meteorological events, alongside with the growing uncertainty in upcoming future pose additional challenges threatening the long-term viability of agricultural systems as such. Therefore, numerous scientists (Almas \& Campbell, 2012; Sawicka, 2019) emphasize that future sustainability of agriculture will increasingly depend on its capacity to withstand various perturbations and to recover from them, in other words - on resilience. Not surprisingly, resilience has been included as one of the priority goals in the upcoming agricultural support agenda of the 2021-2027 financial programing period of the European Union. However, the studies on the economic resilience in agriculture are scarce, fragmented and mainly focused on ecological rather than economical side of the system. The research on how the EU support schemes for agriculture impact the resilience of the sector, - whether these schemes contribute to or on the contrary, hinder resilience building, is especially limited. In order to fill this gap, this paper analyses what determines resilience of the agricultural sector as well as analyses direct and indirect ways in which EU direct payments can influence resilience of the agricultural sector.

\section{Materials and Methods}

This paper is built on the analysis and synthesis of scientific literature, legal documents and statistical data.

Up to date, two main perspectives on resilience can be found in economic literature: so-called 'equilibrium' approaches and the so-called 'nonequilibrium' or 'complex systems' approaches (Bristow \& Healy, 2013). 'Equilibrium' approaches consider an economic system to be relatively simple, homogenous and stationary, finding itself in some kind of equilibrium or growth path that develops in linear, predictable way (Fagiolo, 2016). Systems themselves are usually studied on a single level, separately from their immediate environments, using equilibrium models and normal distribution-based statistics. In the framework of these 'equilibrium' approaches resilience is defined either as the ability of a system to 'bounce back', i.e. to return to a pre-shock equilibrium state or growth path it would have been in if the shock was absent (Fingleton et al., 2012; Angulo, Mur, \& Trivez, 2017), otherwise called engineering resilience, or as the ability to absorb the shocks that '...have the potential to throw it off its growth path but do not actually do so' (Wolman et al., 2017), also known as ecological resilience. 'Non-equilibrium' or adaptive approaches are based on the theory of complex adaptive systems. These systems are characterized by heterogeneity, non-linear complex dynamics, continuous interaction with their environment and operation under a constant uncertainty and change. This complex non-linear dynamics challenge the whole idea of equilibrium, stating that complex adaptive systems are never in equilibrium. Therefore, a return to a previous stable state (equilibrium) after a disturbance may be neither possible (due to a constant change) nor desirable. Moreover, the seemingly stable 
states can suddenly change and become entirely new ones, with different structure, controls and feedbacks (Bristow \& Healy, 2013). Thus, resilience is not viewed as a return to some stable previous state, but rather as a dynamic, evolutionary capacity to adapt in response to perturbations (ibid).

In this paper, the latter approach to resilience is used, defining resilience of an agricultural sector as the capacity of this sector to withstand or recover from various (market, competitive, environmental, etc.) shocks, if necessary, by undergoing adaptive changes to its economic structures and social and institutional arrangements, so as to maintain its core functions (based on definitions proposed by Martin \& Sunley, 2015). The core functions of the agricultural sector here are limited to the provision of private goods (production of affordable food and other bio-based resources, provision of income for farmers and farm workers, and assurance of farm viability), excluding the provision of public goods, since in most cases important trade-offs exist between those two groups of goods. It must also be noted that in this paper general resilience (as opposed to 'specified' resilience) is being explored, focusing on the capacity of a system to react to various kinds of shocks and perturbations, instead of dealing with a particular shock or particular aspect of the system that might be affected by that shock (Biggs et al., 2012).

Determinants of resilience. There is a lot of research dedicated to finding out the factors determining the resilience of an economic system. However, this question is still open - there is no consensus neither on the set of factors potentially influencing resilience, nor on their significance, or on the idea if such universal factors (influencing resilience across time and space) can be determined on the whole.

Studies of resilience are performed at various levels - micro (individual, household, business, government agency), meso (individual sector, industry or market) and macro (operation of the economy, combination of all economic entities on a certain territory), and the greater share of those studies focus on system's features as determinants of resilience. Different authors identify different sets of such features influencing resilience. However, - one of the most analyzed aspects is the system's economic structure (Darnhofer et al., 2010; Cabell \& Oelofse, 2012; Martin \& Sunley, 2015; Angulo, Mur, \& Trívez, 2017). One of the most analyzed topics in this area is whether system's specialization or diversification leads to resilience. Many authors (Davies \& Tonts, 2010; Doran \& Fingleton, 2013) argue that diversification is a way to increase resilience. Their inferences are based on reasoning that since different types of industry, sectors, subsectors, elements, etc. have different characteristics (e.g. different (sub) sectors have different elasticities of demand, different knowledge, labor and capital intensities, different export orientations, different production cycles, different vulnerabilities to various risks, etc.), the diversified system should be less susceptible to some particular shock than a specialized one. The former should also recover faster since it would have more options to act upon and more alternative ways to adapt and recover (Evans \& Karecha, 2013). However, empirical evidence shows that diversified systems are not always more resilient than specialized ones (Martin et al., 2016). Therefore, some scholars argue that it is not only the level of diversity or specialization that matters, but also how the elements in the system are interconnected as well as the availability of unspecific and uncommitted capacities that can be put to a variety of unforeseeable uses (Boshma, 2015).

The other factor, almost universally identified as having a very significant influence on system's resilience, is education of human agents of that particular system (Cabell \& Oelofse, 2012; Martin \& Sunley, 2015; Bristow \& Healy, 2017). It is wellknown that a well-qualified and skilled workforce contributes to higher productivity of businesses, and the higher the productivity of the firms the more resilient they are likely to be (Martin et al., 2016). It also provides the local economy as a whole with greater scope for adapting out of major crises (ibid). Population age, entrepreneurship and people's attitudes and expectations are also considered as very important factors determining resilience of a system (Martin \& Sunley, 2015; Obschonka et al., 2016).

Other factors that various authors classify as having important impact on resilience can be grouped in several categories, corresponding to the economic, social, ecological and political dimensions of a system, analyzed at three levels (micro, meso and macro). Economic dimension comprises such factors as macroeconomic indicators (Angeon \& Bates, 2015; Martin et al., 2016), access to resources (Darnhofer, Fairweather, \& Moller, 2010; Martin et al., 2016; Wink et al., 2018), infrastructure (Boto \& PandyaLorch, 2013), export diversity (Angeon \& Bates, 2015; Wink et al., 2018; Morkūnas et al., 2018) and business characteristics (Cabell \& Oelofse, 2012; Wink et al., 2018). Social factors encompass connections and networks (Martin \& Sunley, 2015; Boschma, 2015; Sabatino, 2019) as well as social norms, values, customs and traditions (Biggs et al., 2012; Martin \& Sunley, 2015; Bristow \& Healy, 2017). Legislative frameworks and government economic policies and support are important both, during the shock, as well as in periods before it (Boto \& Pandya-Lorch, 2013; Angeon \& Bates, 2015; Wink et al., 2018). Ecological dimension covers such factors as landscape and biodiversity, soil quality, etc., which are especially 
relevant for the resilience of the agricultural sector (Cabell \& Oelofse, 2012; Altieri \& Nicholls, 2017).

Empirical evidence shows, however, that despite very similar features of the two systems, their resilience may differ profoundly and standard macro-economic models struggle to account for resilience at the meso or macro levels (Martin et al., 2016; Obschonka et al., 2016). One of the main reasons of such a difference may be due to the neglect of human behavior and its role for resilience. However, human behavior is one of the core determinants of the resilience and many researchers agree on that (Martin \& Sunley, 2015; Obschonka et al., 2016; Wolman et al., 2017). Almost all the developments at the macro level depend on the activities at the micro level and any outcome at the micro level depends on the human action or inaction, since inaction is also an action, the behavior of the myriad of economic agents before the shock and after it determines if the whole system will be resilient or not. Of course, the context and environmental conditions also matter but not by their mere existencethey matter as options of possible choices from which a human chooses which ones to exploit. A wide array of research (Martin \& Sunley, 2015; Obschonka et al., 2016) shows that regions subject to the same macroeconomic forces and having similar economic structure perform very differently. It is because with the same set of structural elements there is a huge set of possible choices. Which ones would be selected depend first of all on the human agency (individual or collective). Recently behavior, especially particular types of it, is getting more and more attention by economists studying resilience. Although empirical findings are still quite scarce, many researchers tend to mention several behavior patterns that lead to resilience in multiple contexts, namely: creating and absorbing innovations (Darnhofer et al., 2010; Martin \& Sunley, 2015; Obschonka et al., 2016; Bristow \& Healy, 2017; Wink et al., 2018), learning (increasing qualifications and improving skills) (Biggs et al., 2012; Sellberg et al., 2018), collaborating and cooperating (Cabell \& Oelofse, 2012; Biggs et al., 2012; Boschma, 2015, Martin et al., 2016; Bristow \& Healy, 2017; Sellberg et al., 2018), managing risks (Marchall et al., 2012; Boto \& Pandya-Lorch, 2013; Linkov et al., 2014; Martin et al., 2016) participating (Cabell \& Oelofse, 2012; Wink et al., 2018; Sellberg et al., 2018), sustainably managing resources (Darnhofer et al., 2010; Cabell \& Oelofse, 2012), and enabling polycentric governance (does not apply to micro level) (Biggs et al., 2012).

Taking into account the research on resilience determinants provided above, it could be argued that resilience of the agricultural sector as a socio-economic system depends on the behavior of various agents interacting among each other inside the system as well as with other agents outside it by their behavior being

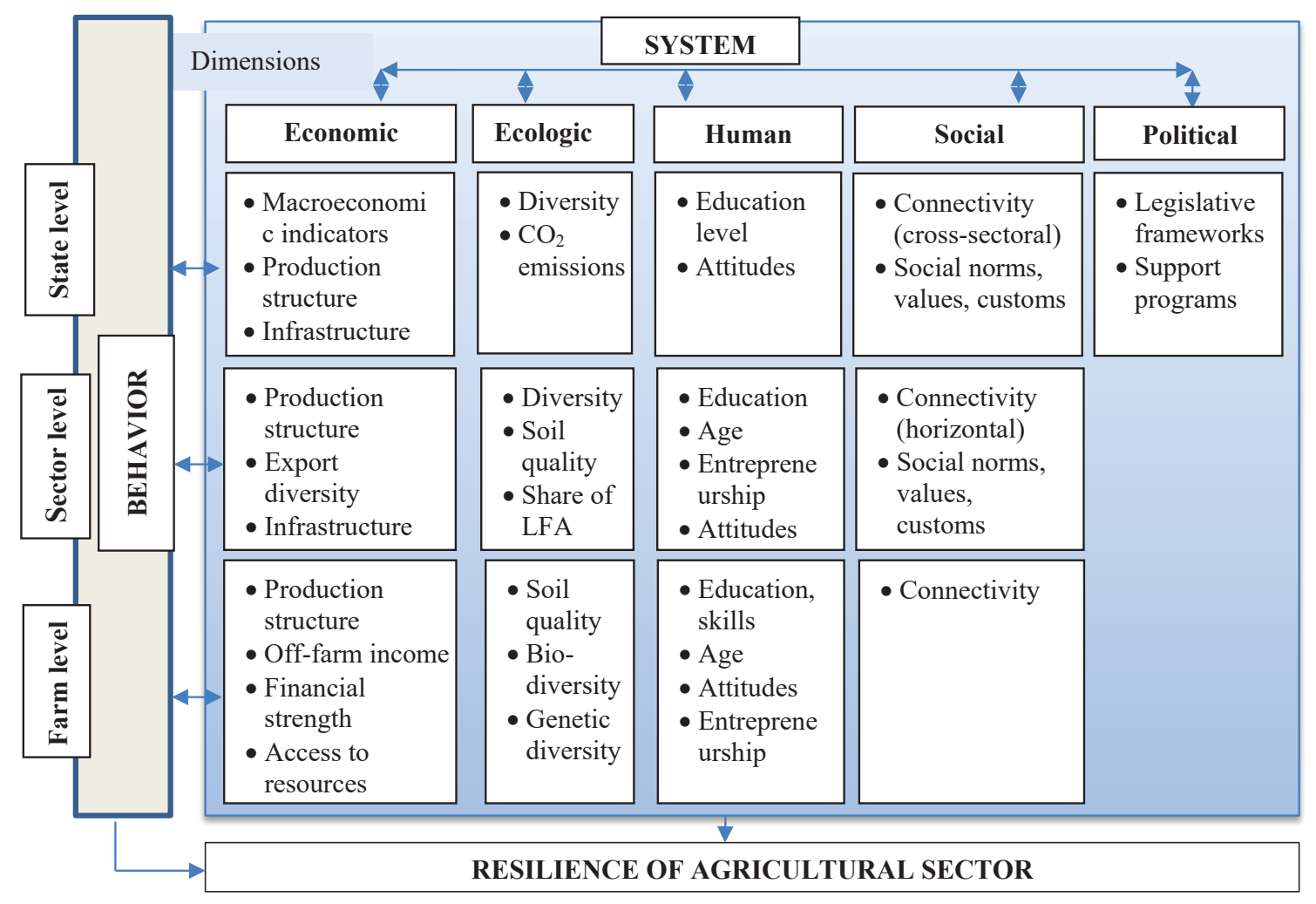

Figure 1. Factors, potentially determining resilience of the agricultural sector.

Source: compiled by the author. 


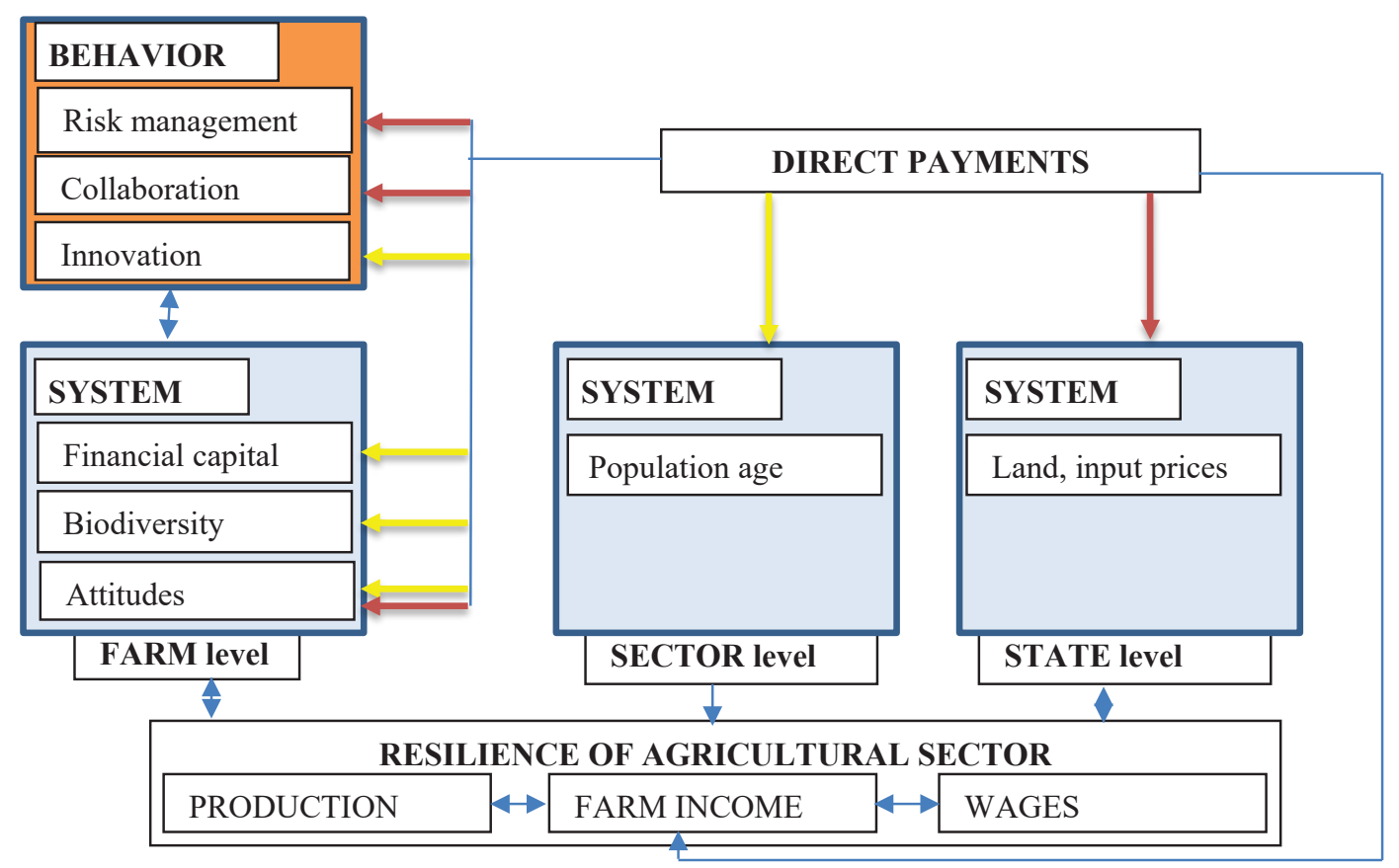

Figure 2. Model of CAP DP impact (yellow positive, red - negative) on the resilience of agricultural sector. Source: compiled by the author.

reciprocally influenced by the system's characteristics as well as each other's actions (Figure 1).

Direct payments and their impact on resilience of agricultural sector. Direct payments (DP) are one of the main support measures of Common Agricultural Policy (CAP), accounting for more than $70 \%$ of total support for agriculture (and more than $26 \%$ of the whole EU budget) in 2014-2020 period. They represent around $30 \%$ of farm income (differing between farming types and different states) and are aimed at increasing and stabilizing farm income as well as supporting farmers to deliver a multiplicity of goods and services (Severini et al., 2016).

However, even if DP perform the incomestabilizing role, they may also have unintended impacts on farmers' behavior, which could in turn significantly influence the resilience of the whole agricultural sector. Based on the literature review, it can be argued that DP have a direct impact on resilience (by increasing farmers income and guaranteeing stability of this share of income) as well as significant indirect repercussions by influencing system features and behavior that affect resilience (Figure 2).

\section{Results and Discussion.}

Starting at the macro level, DP first of all negatively impact (increase) input and land (rental) prices. There is an extensive body of literature on this topic (Kirwan \& Roberts, 2016; Severini et al., 2016; Graubner, 2018). Empirical evidence suggests partial incidence of up to 50 percent and more, i.e. subsidies up to half of their value are reflected in land prices (Latruffe \& Le Mouël, 2009).

DP, guaranteeing stable incomes, as well as additional payments specifically for young farmers (in many EU states), contributes to attracting them to agricultural business as well as to keeping them in it (Volkov et al., 2019; May et al., 2019). The system with a population with a relatively higher share of younger age individuals is usually indicated as more resilient, since younger people are usually more flexible, mobile and have more abilities to adapt to changing conditions (Martin et al., 2016).

The largest influence of DP on resilience is, however, made through the micro level, since these payments are paid directly to farmers, impacting their income, attitudes and behavior. A great share of research dedicated to DP's impact on behavior is associated with risk management (Marchall et al., 2012; Boto \& Pandya-Lorch, 2013; Linkov et al., 2014). Many researchers have studied the relationship between DP and insurance adoption and have concluded that payments do influence farmers' decisions not to adopt crop/animal insurance: Chakir \& Hardelin (2014) have shown that subsidies negatively affected insurance demand in rapeseed production in France, and Finger \& Lehmann's (2012) study results indicate that the larger the share of direct payments for total farm revenue, the less attractive are insurances as risk management strategy for farmers. This can be due to several reasons: first, the stability of incomes has an insurance effect in themselves, and 


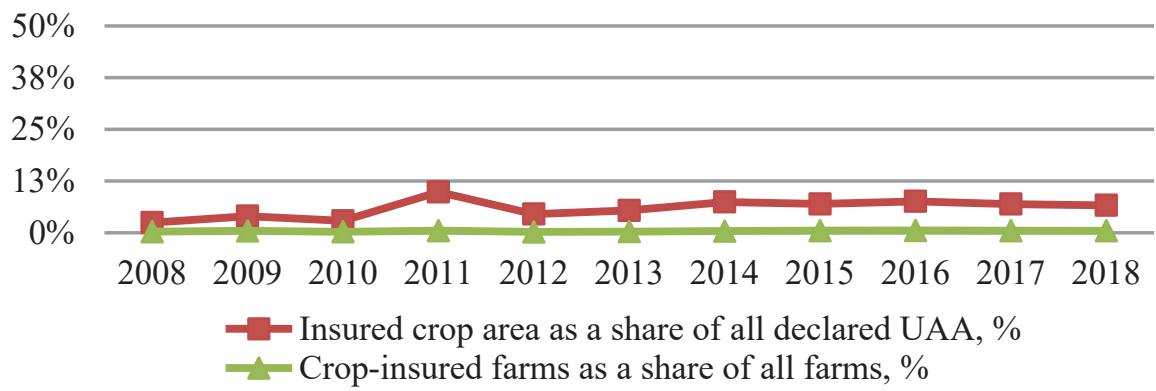

Figure 3. A share of insured crop area and a share of farms holding crop insurance in the period 2008-2018 in Lithuania.

Source: based on data obtained from the Ministry of Agriculture of the Republic of Lithuania.

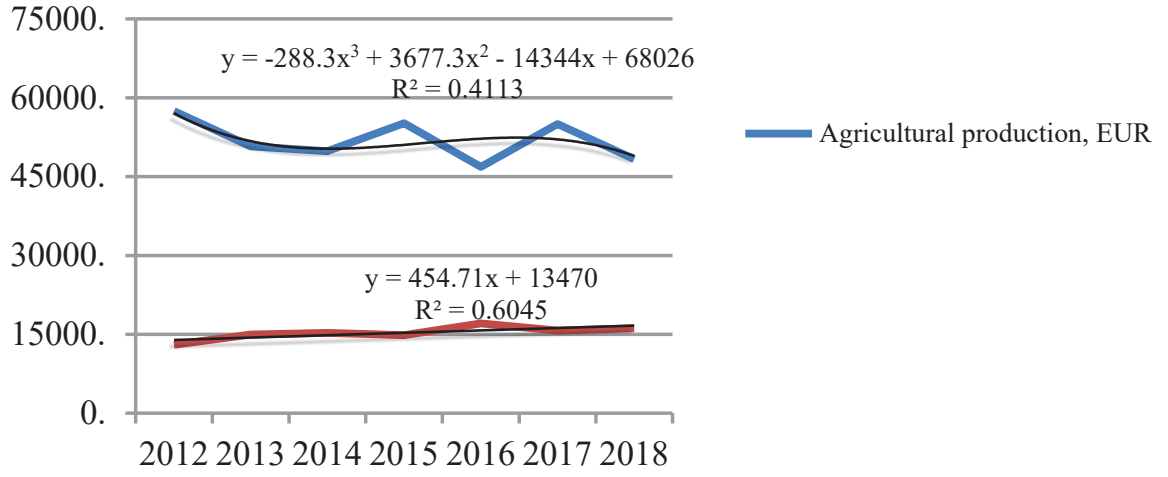

Figure 4. Average agricultural production and subsidies (direct payments,

LFA and ecological farming) of an average Lithuanian farm in the period 2012-2018.

Source: compiled by author, based on FADN data.

second, DP income might increase farmers' wealth, and if farmers are risk-averse, they are expected to decrease their level of risk aversion, thus decreasing farmers' demand for insurances (Kimura et al., 2010; Finger \& Lehmann, 2012). These reasons can explain why the uptake of insurance is so low in the majority of EU states. Lithuania is not an exception. Although the conditions for taking up insurance here are very favorable (the state has been subsidizing up to $65 \%$ of insurance premiums for a number of years), the uptake of insurance is very low - more than $95 \%$ of farmers do not insure their risks (Figure 3).

The other potential way how the DP influence farmers' risk management behavior is by changing their production decisions. Capitanio et al. (2014) notes that DP, on the one hand, can encourage farmers to invest and increase his production capacity, however, on the other hand, farmers can use this additional money as a substitute to his activity, decreasing their agricultural production. That may be the case in Lithuania, where agricultural production (crop and animal) is decreasing while subsidies are increasing (Figure 4).

DP, even decoupled, could continue influencing farmers' decisions on the production structure, encouraging them to grow/produce the sorts of production that was (or still is) coupled with DP instead of growing/producing the sorts most required by the market and potentially more profitable (Breen et al., 2005). It is also argued, that DP have an impact on the level of diversification on the farm (Mishra et al., 2004; Maye et al., 2009), which in turn significantly influences farm's resilience.

These examples together with other possible DP impacts on behavior show that DP influence on resilience is multidimensional and in many cases involve behavior (and attitude) change. In order to get a deeper view on the possible DP influence on behavior of Lithuanian farmers, an extensive survey is being carried out. Preliminary results should be available at the time of the conference. Results from the survey, as well as the statistical data, will be used to analyze the impact of DP on Lithuanian agricultural sector.

\section{Conclusions}

1. The future sustainability of agriculture will increasingly depend on its resilience - capacity to withstand various perturbations and recover from them. In order to increase resilience of this sector, 
it is necessary to know what factors (conditions) help boost it, and what hinder its development. However, studies of economic resilience in agriculture are scarce, fragmented and mainly focused on ecological rather than economical side of the system.

2. In order to fill this gap, an extensive literature review was performed and a summarized list of factors that are mentioned as potentially influencing resilience prepared. These factors were classified under two broad groups: system features and behavioral patterns. The analysis of the literature shows that most important behavioral patterns contributing to increasing resilience are learning, innovation, collaboration and risk management.
3. EU direct payments are the most financed EU support scheme for agriculture; however, research on its impact on the resilience of the sector is especially limited. In this paper, it is argued that these payments have a direct as well as a strong indirect impact on resilience. This impact is transferred mostly through changing farms' financial capabilities as well as farmers' attitudes and behaviors, and is argued to be both positive and negative. Such phenomena as low crop insurance uptake and decrease in productivity may be due to the overcrowding effects of direct payments. These hypotheses are being tested in the survey which is being conducted in the meantime.

\section{References}

Almås, R., \& Campbell, H. (2012). Introduction. Rethinking Agricultural Policy Regimes Research in Rural Sociology and Development, 1-22. DOI: 10.1108/s1057-1922(2012)0000018003.

Altieri, M.A., \& Nicholls, C.I. (2017). The adaptation and mitigation potential of traditional agriculture in a changing climate. Climatic Change, 140 (1), 33-45.

Angeon, V., \& Bates, S. (2014). Reviewing Composite Vulnerability and Resilience Indexes: A Sustainable Approach and Application. SSRN Electronic Journal. DOI: 10.2139/ssrn.2437980.

Angulo, A.M., Mur, J., \& Trívez, F.J. (2017). Measuring resilience to economic shocks: an application to Spain. The Annals of Regional Science, 60(2), 349-373. DOI: 10.1007/s00168-017-0815-8.

Biggs, R., Schlüter, M., Biggs, D., Bohensky, E.L., BurnSilver, S., Cundill, G., ... West, P.C. (2012). Toward principles for enhancing the resilience of ecosystem services. Annual Review of Environment and Resources, 37, 421-448.

Boschma, R. (2015). Towards an Evolutionary Perspective on Regional Resilience. Regional Studies, 49(5), 733-751. DOI: 10.1080/00343404.2014.959481.

Boto, I., \& Pandya-Lorch, R. (2013). Agricultural resilience in the face of crisis and shocks. Brussels Rural Development Briefings. Retrieved February 19, 2020, from https://brusselsbriefings.files.wordpress. com/2009/02/cta-reader-30_agricultural-resilience-eng-rev-2.pdf.

Breen, J.P., Hennessy, T.C., \& Thorne, F.S. (2005). The effect of decoupling on the decision to produce: An Irish case study. Food Policy, 30(2), 129-144. DOI: 10.1016/j.foodpol.2005.03.001.

Bristow, G., \& Healy, A. (2013). Regional Resilience: An Agency Perspective. Regional Studies, 48(5), 923935. DOI: $10.1080 / 00343404.2013 .854879$.

Bristow, G., \& Healy, A. (2017). Innovation and regional economic resilience: an exploratory analysis. The Annals of Regional Science, 60(2), 265-284. DOI: 10.1007/s00168-017-0841-6.

Cabell, J.F., \& Oelofse, M. (2012). An Indicator Framework for Assessing Agroecosystem Resilience. Ecology and Society, 17(1), DOI: 10.5751/es-04666-170118.

Capitanio, F., Adinolfi, F., Enjolras, G., \& Aubert, M. (2014). Direct payments, crop insurance and the volatility of farm income: some evidence in France and in Italy. New Medit, 13(1), 31-40.

Chakir, R., \& Hardelin, J. (2014). Crop Insurance and pesticide use in French agriculture: an empirical analysis. Revue d'Études En Agriculture Et Environnement, 95(01), 25-50. DOI: 10.4074/s1966960714011035.

Darnhofer, I., Bellon, S., Dedieu, B., \& Milestad, R. (2011). Adaptiveness to Enhance the Sustainability of Farming Systems. Sustainable Agriculture Vol. 2, 45-58. DOI: 10.1007/978-94-007-0394-0_4.

Davies, A., \& Tonts, M. (2009). Economic Diversity and Regional Socioeconomic Performance: An Empirical Analysis of the Western Australian Grain Belt. Geographical Research, 48(3), 223-234.

Doran, J., \& Fingleton, B. (2017). US MetropolitanArea Resilience: Insights from dynamic spatial panel estimation. Environment and Planning A: Economy and Space, 50(1), 111-132. DOI: 10.1177/0308518x17736067.

Evans, R., \& Karecha, J. (2013). Staying on Top: Why is Munich so Resilient and Successful? European Planning Studies, 22(6), 1259-1279. DOI: 10.1080/09654313.2013.778958.

Fagiolo, G. (2016). Macroeconomic Policy in DSGE and Agent-Based Models Redux: New Developments and Challenges Ahead. SSRN Electronic Journal. DOI: 10.2139/ssrn.2763735. 
Finger, R., \& Lehmann, N. (2012). The influence of direct payments on farmers' hail insurance decisions. Agricultural Economics, 43(3), 343-354. DOI: 10.1111/j.1574-0862.2012.00587.x.

Fingleton, B., Garretsen, H., \& Martin, R. (2012). Recessionary Shocks and Regional Employment: Evidence on the Resilience of U.K. Regions. Journal of Regional Science, 52(1), 109-133. DOI: 10.1111/j.14679787.2011.00755.x.

Graubner, M. (2017). Lost in space? The effect of direct payments on land rental prices. European Review of Agricultural Economics, 45(2), 143-171. DOI: 10.1093/erae/jbx027.

Kimura, S., Antón, J., \& LeThi, C. (2010). Farm Level Analysis of Risk and Risk Management Strategies and Policies. OECD Food, Agriculture and Fisheries Papers. DOI: 10.1787/5kmd6b5rl5kd-en.

Kirwan, B.E., \& Roberts, M.J. (2016). Who Really Benefits from Agricultural Subsidies? Evidence from Fieldlevel Data. American Journal of Agricultural Economics, 98(4), 1095-1113. DOI: 10.1093/ajae/aaw022.

Latruffe, L., \& Mouël, C.L. (2009). Capitalization Of Government Support In Agricultural Land Prices: What Do We Know? Journal of Economic Surveys, 23(4), 659-691. DOI: 10.1111/j.1467-6419.2009.00575.

Linkov, I., Bridges, T., Creutzig, F., Decker, J., Fox-Lent, C., Kröger, ... Thiel-Clemen, T. (2014). Changing the resilience paradigm. Nature Climate Change, 4, 407-409.

Martin, R., \& Sunley, P. (2015). On the notion of regional economic resilience: conceptualization and explanation. Journal of Economic Geography, 15(1), 1-42. DOI: 10.1093/jeg/lbu015.

Martin, R., Sunley, P., Gardiner, B., \& Tyler, P. (2016). How Regions React to Recessions: Resilience and the Role of Economic Structure. Regional Studies, 50(4), 561-585. DOI: 10.1080/00343404.2015.1136410.

May, D., Arancibia, S., Behrendt, K., \& Adams, J. (2019). Preventing young farmers from leaving the farm: Investigating the effectiveness of the young farmer payment using a behavioural approach. Land Use Policy, 82, 317-327.

Maye, D., Ilbery, B., \& Watts, D. (2009). Farm diversification, tenancy and CAP reform: Results from a survey of tenant farmers in England. Journal of Rural Studies, 25(3), 333-342. DOI: 10.1016/j.jrurstud.2009.03.003.

Mishra, A.K., El-Osta, H.S., \& Sandretto, C.L. (2004). Factors affecting farm enterprise diversification. Agricultural Finance Review, 64(2), 151-166. DOI: 10.1108/00214660480001160.

Morkūnas, M., Volkov, A., \& Pazienza, P. (2018). How Resistant is the Agricultural Sector? Economic Resilience Exploited. Economics \& Sociology, 11(3), 321-332. DOI: 10.14254/2071-789x.2018/11-3/19.

Obschonka, M., Stuetzer, M., Audretsch, D.B., Rentfrow, P.J., Potter, J., \& Gosling, S.D. (2015). Macropsychological Factors Predict Regional Economic Resilience During a Major Economic Crisis. Social Psychological and Personality Science, 7(2), 95-104. DOI: 10.1177/1948550615608402.

Sabatino, M. (2019). Economic resilience and social capital of the Italian region. International Review of Economics \& Finance, 61, 355-367. DOI: 10.1016/j.iref.2019.02.011.

Sawicka, B. (2019). Resilient Agricultural Practices. Handbook of the Historiography of Biology Historiographies of Science, 1-13. DOI: 10.1007/978-3-319-69626-3_42-1.

Sellberg, M., Ryan, P., Borgström, S., Norström, A., \& Peterson, G. (2018). From resilience thinking to Resilience Planning: Lessons from practice. Journal of Environmental Management, 217, 906-918. DOI: 10.1016/j.jenvman.2018.04.012.

Severini, S., Tantari, A., \& Tommaso, G.D. (2016). Do CAP direct payments stabilise farm income? Empirical evidences from a constant sample of Italian farms. Agricultural and Food Economics, 4(1), DOI: 10.1186/ s40100-016-0050-0.

Volkov, A., Balezentis, T., Morkunas, M., \& Streimikiene, D. (2019). Who Benefits from CAP? The Way the Direct Payments System Impacts Socioeconomic Sustainability of Small Farms. Sustainability, 11(7), 2112. DOI: $10.3390 /$ su11072112.

Wink, R., Kirchner, L., Koch, F., \& Speda, D. (2018). The economic resilience of Stuttgart: vulnerable but resilient and adaptable. Economic Crisis and the Resilience of Regions, 41-60. DOI: 10.4337/9781785364006.00008.

Wolman, H., Wial, H., Clair, T.S., \& Hill, E. (2017). Shocks and Regional Economic Resilience. Coping with Adversity. DOI: 10.7591/cornell/9780801451690.003.0002. 